\title{
Point-of-Care Airway Ultrasonography Prior to an Emergency Cricothyroidotomy Case report
}

"Mohamad Iqhbal, Julina M. Noor, Nur A. Karim, Izzat Ismail, Halim Sanib, Mohd A. Mokhtar, Safreeda S. F. Salim

$$
\text { نقطة الرعاية للمسلك الهوائي بتخطيط الصدى قبل عملية بضع الغشاء الحلقي اللقرقي الطارئة }
$$

محمد إقبال، جولينا محمد نور، نور عبدالكريم، إيزات إسماعيل، حليم سنيب، محمد أمين مختار، صفريدا سالم

ABSTRACT: The use of ultrasonography in acute and critical care medicine is becoming increasingly common. However, use of an airway ultrasound as an adjunct to determine the type of intervention needed and assess complications is not common practice. We report a 56-year-old male who presented to the Emergency Department of the Sungai Buloh Hospital, Selangor, Malaysia, in 2015 with hoarseness, stridor and impending respiratory failure. A point-of-care ultrasound performed to assess the neck and vocal cords indicated a heterogeneous echogenic mass in the larynx, thus ruling out a cricothyroidotomy. The patient was therefore referred for an emergency tracheostomy. This case highlights the importance of point-of-care airway ultrasonography in the assessment of patients with stridor. This imaging technique not only helps to detect the cause of the stridor, but also to determine the feasibility of a cricothyroidotomy in emergency cases.

Keywords: Emergency Medicine; Stridor; Ultrasonography; Airway Management; Tracheostomy; Case Report; Malaysia.

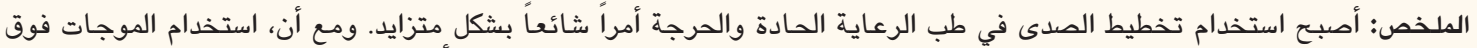

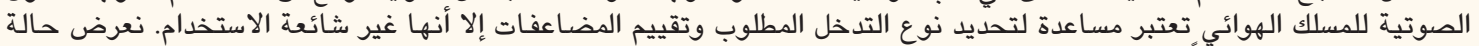

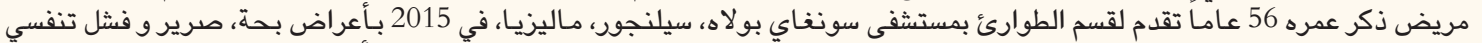

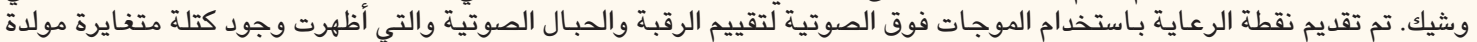

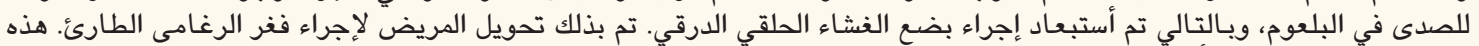

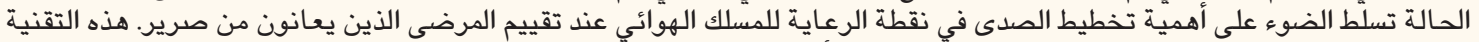

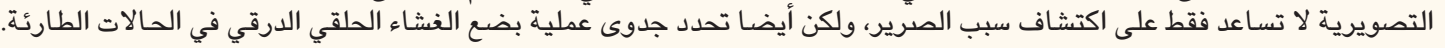

$$
\begin{aligned}
& \text { الكلمات المفتاحية: طب الطوارئ؛ صرير؛ تخطيط الصدى؛ علاج المسلك الهوائي؛ فغر الرغامى؛ تقرير حالة؛ ماليزيا. }
\end{aligned}
$$

\section{$\mathrm{T}$} He PRESENCE OF STRIDOR INDICATES AN upper airway obstruction. ${ }^{1}$ In emergency departments, patients with stridor are often treated emergently according to strict management protocols. In such cases, the attending physician must be able to evaluate the patient and determine the type of airway management intervention required, such as a cricothyroidotomy. ${ }^{1}$ However, with the high rate of success of newer airway management techniques, such as orotracheal intubation, rates of cricothyroidotomies have declined over the past decade to approximately $0.4-1.2 \% .^{2-5}$

Unfortunately, as this procedure is uncommon, the prevalence of complications during a cricothyroidotomy can vary from $6.1-54.5 \%$, depending on the clinical circumstances of the case, technique employed and experience of the surgeon. ${ }^{6,7}$ Although point- of-care ultrasonography (POCUS) is very useful in critical care and acute medicine, its role in airway management is not routine, even though several studies have advocated its use. ${ }^{8-10}$ The current case demonstrates the benefits of POCUS in assessing the airway of a patient with stridor and informing the choice of emergency airway intervention.

\section{Case Report}

A 56-year-old male presented to the Emergency Department of the Sungai Buloh Hospital, Selangor, Malaysia, in 2015 with shortness of breath, stridor and hoarseness. He had started experiencing breathing difficulties and coryzal symptoms a few months previously. The patient reported that the hoarseness had begun about six months prior to presentation and 

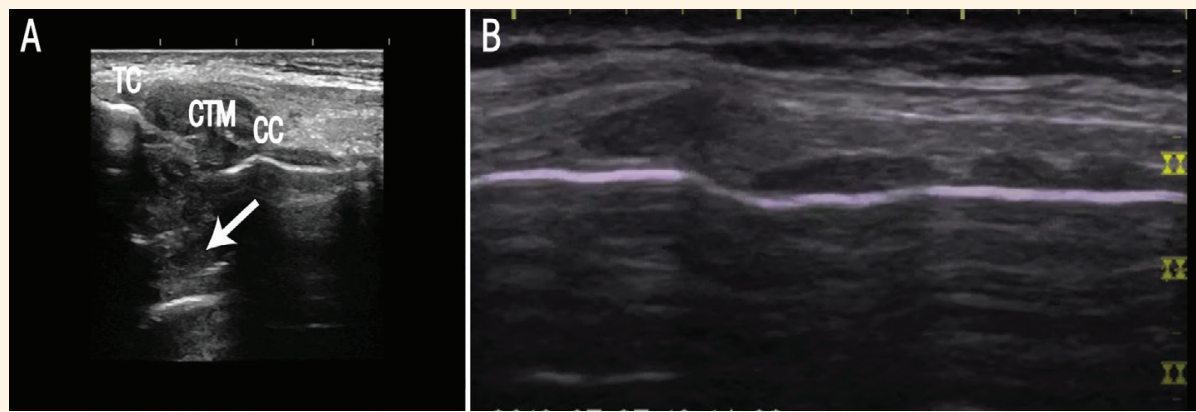

Figure 1: Longitudinal point-of-care airway ultrasonography of (A) a 56-year-old male with stridor showing a distorted cricothyroid membrane with a mass underneath (arrow) in comparison to (B) an example of a normal airway. $T C=$ thyroid cartilage; $C T M=$ cricothyroid membrane; $C C=$ cricoid cartilage.
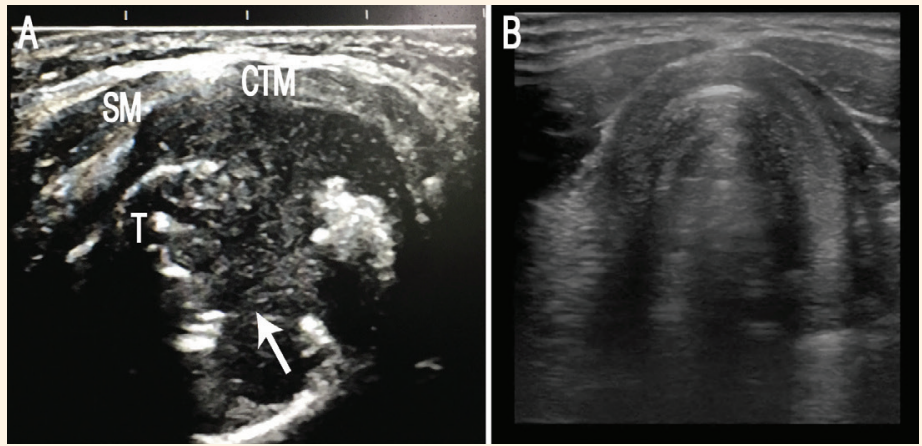

Figure 2: Transverse point-of-care airway ultrasonography of (A) the airway of a 56-year-old male with stridor showing intraluminal heterogeneous echogenic mass (arrow) in comparison to (B) an example of a normal airway.

SM = sternohyoid muscle; $C T M=$ cricothyroid membrane; $T$ = trachea .

was associated with weight loss, loss of appetite and dysphagia. However, he was still able to eat and drink. He had seen a local general practitioner but these symptoms had not been investigated. One week prior to presentation, he started to experience noisy breathing precipitated by an upper respiratory tract infection and he reported feeling breathless upon exertion.

At presentation, the patient could sit upright and was mildly tachypnoeic with inspiratory stridor. His breathing sounds were normal and he was able to talk in a hoarse voice without drooling. His blood pressure

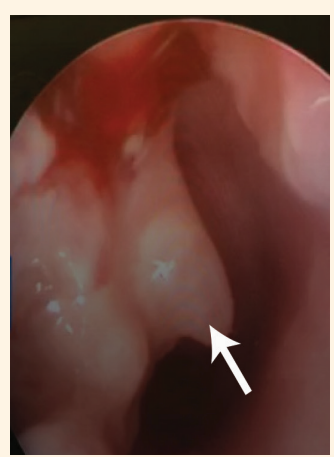

Figure 3: Flexible laryngoscopic image of the airway of a 56-year-old male showing an intraluminal fungating mass (arrow). was 118/80 $\mathrm{mm} \mathrm{Hg}$ and he had a pulse rate of 70 beats per minute. Oxygen saturation was at $98 \%$ with a nasal cannula. A clinical examination revealed no visible mass in the head, neck or chest region and the trachea appeared to be centrally located. There were also no signs of venous distension of the neck or chest wall or evidence of facial or upper extremity oedema. An airway ultrasound was performed to investigate the structure of the airway and identify the cause of the stridor. Notably, this revealed a hyperechoic artefact extending throughout the cricoid cartilage, which was inconsistent with the structure of a normal airway [Figure 1]. The mass had ill-defined borders with heterogeneous echogenicity [Figure 2].

Anticipating that airway management would be difficult and potentially involve intubation or a cricothyroidotomy, the patient was referred to the otorhinolaryngology team for further assessment and definitive management. Flexible laryngoscopy revealed a fungating mass involving the false vocal cords and extending to the subglottic region [Figure 3]. As the patient was stable and able to maintain oxygenation, he underwent an emergency tracheostomy. Later, a computed tomography scan was suggestive of a laryngeal carcinoma [Figure 4], which was successfully removed. 


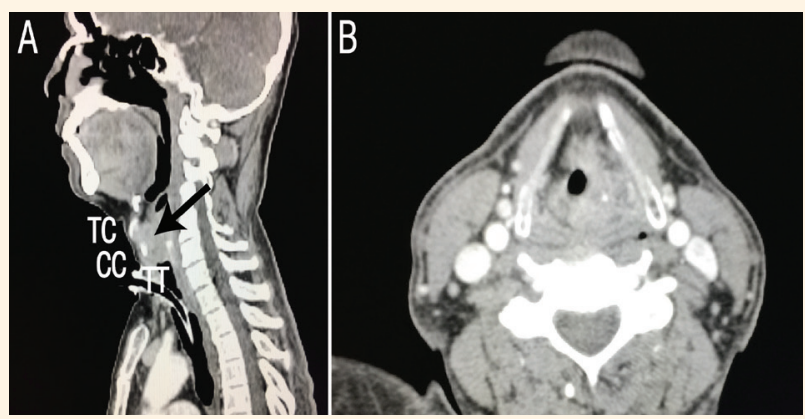

Figure 4: Computed tomography scans of the airway of a 56-year-old male in the (A) sagittal view showing an irregular mass obstruction (arrow) extending to the lower border of the cricoid cartilage and (B) axial view showing the severely stenosed airway.

$T C=$ thyroid cartilage; $C C=$ cricoid cartilage $T T$ = tracheostomy tube

\section{Discussion}

In acute care medicine, delays in airway management can result in poor outcomes. ${ }^{11}$ Emergency airway interventions range from laryngoscopy to a cricothyroidotomy, with the latter being a last life-saving resort when all other measures fail. Traditionally, a cricothyroidotomy is performed blindly as a form of emergent airway management. ${ }^{12}$ Prior to the procedure, the cricothyroid membrane is identified based on surface landmarks and palpation. However, Elliott et al. demonstrated that this membrane was only correctly identified by $30 \%$ of anaesthetists, of which only $11 \%$ could locate the midline..$^{13}$ In such cases, the cricothyroidotomy tube can be misplaced due to the inaccurate identification of these anatomical landmarks. In addition, technical problems in 40\% of cases have been noted during cricothyroidotomies performed using the Seldinger technique. ${ }^{14}$

In comparison, POCUS is a noninvasive and readily available technique. Furthermore, it can provide detailed information regarding the anatomy of the airway as all of the internal structures can be visualised in a short period of time by placing the linear probe at the centre of the neck. ${ }^{15}$ Prior to an emergency cricothyroidotomy, an ultrasound allows for the reliable and rapid identification of the cricothyroid membrane and trachea, unaffected by the patient's body mass index. ${ }^{16,17}$

The current case highlights the importance of POCUS, not only in the accurate localisation of anatomical landmarks, but also in the identification of any internal structural abnormalities and, consequently, the feasibility of performing a cricothyroidotomy. While it may be argued that POCUS is not expedient in a time-sensitive situation, failure and complication rates remain high for emergency cricothyroidotomies performed blindly, thus delaying critical life-saving interventions in any case..$^{18}$ As such, the authors advocate the incorporation of POCUS-guided crico- thyroidotomy skills in emergency medicine and critical care training, particularly in view of the reliability of this technique and its association with fewer complications compared to conventional methods. ${ }^{16}$

\section{Conclusion}

Routine POCUS should be considered in certain highrisk situations requiring emergency airway management, such as stridor and neck haematomas and masses. In such cases, the identification of an abnormal anatomical structure in the airway would make a conventional cricothyroidotomy unfeasible; hence, an alternative approach is required, such as a tracheostomy.

\section{References}

1. Nemeth J, Maghraby N, Kazim S. Emergency airway management: The difficult airway. Emerg Med Clin North Am 2012; 30:401-20. doi: 10.1016/j.emc.2011.12.005.

2. Bushra JS, McNeil B, Wald DA, Schwell A, Karras DJ. A comparison of trauma intubations managed by anesthesiologists and emergency physicians. Acad Emerg Med 2004; 11:66-70. doi: 10.1197/j.aem.2003.08.013.

3. Tayal VS, Riggs RW, Marx JA, Tomaszewski CA, Schneider RE. Rapid-sequence intubation at an emergency medicine residency: Success rate and adverse events during a two-year period. Acad Emerg Med 1999; 6:31-7. doi: 10.1111/j.1553-2712.1999. tb00091.x.

4. Sakles IC, Laurin EG, Rantapaa AA, Panacek EA. Airway management in the emergency department: A one-year study of 610 tracheal intubations. Ann Emerg Med 1998; 31:325-32. doi: 10.1016/S0196-0644(98)70342-7.

5. Levitan RM, Rosenblatt B, Meiner EM, Reilly PM, Hollander JE. Alternating day emergency medicine and anesthesia resident responsibility for management of the trauma airway: A study of laryngoscopy performance and intubation success. Ann Emerg Med 2004; 43:48-53. doi: 10.1016/S0196-0644(03)00638-3.

6. Bair AE, Panacek EA, Wisner DH, Bales R, Sakles IC. Cricothyrotomy: A 5-year experience at one institution. J Emerg Med 2003; 24:151-6. doi: 10.1016/S0736-4679(02)00715-1.

7. Brantigan CO, Grow JB Sr. Cricothyroidotomy: Elective use in respiratory problems requiring tracheotomy. J Thorac Cardiovasc Surg 1976; 71:72-81. 
8. Whitson MR, Mayo PH. Ultrasonography in the emergency department. Crit Care 2016; 20:227. doi: 10.1186/s13054-0161399-x.

9. Osman A, Sum KM. Role of upper airway ultrasound in airway management. J Intensive Care 2016; 4:52. doi: 10.1186/s40560016-0174-z.

10. Kristensen MS, Teoh WH, Graumann O, Laursen CB. Ultrasonography for clinical decision-making and intervention in airway management: From the mouth to the lungs and pleurae. Insights Imaging 2014; 5:253-79. doi: 10.1007/s13244-014-0309-5.

11. Bauer PR, Gajic O, Nanchal R, Kashyap R, Martin-Loeches I, Sakr Y, et al. Association between timing of intubation and outcome in critically ill patients: A secondary analysis of the ICON audit. J Crit Care 2017; 42:1-5. doi: 10.1016/j.jcrc.2017.06.010.

12. Shannon NJ, Shannon GD. "Blind" emergency cricothyrotomy in patients with complicating factors under adverse conditions. Wilderness Environ Med 1998; 9:260-1. doi: 10.1580/ 1080-6032(1998)009[0260:LTTE]2.3.CO;2.

13. Elliott DS, Baker PA, Scott MR, Birch CW, Thompson JM. Accuracy of surface landmark identification for cannula cricothyroidotomy. Anaesthesia 2010; 65:889-94. doi: 10.1111/ j.1365-2044.2010.06425.x.
14. Eisenburger P, Laczika K, List M, Wilfing A, Losert H, Hofbauer R, et al. Comparison of conventional surgical versus Seldinger technique emergency cricothyrotomy performed by inexperienced clinicians. Anesthesiology 2000; 92:687-90. doi: 10.1097/ 00000542-200003000-00012.

15. Singh M, Chin KJ, Chan VW, Wong DT, Prasad GA, Yu E. Use of sonography for airway assessment: An observational study. J Ultrasound Med 2010; 29:79-85. doi: 10.7863/jum.2010.29.1.79.

16. Nicholls SE, Sweeney TW, Ferre RM, Strout TD. Bedside sonography by emergency physicians for the rapid identification of landmarks relevant to cricothyrotomy. Am J Emerg Med 2008; 26:852-6. doi: 10.1016/j.ajem.2007.11.022.

17. Curtis K, Ahern M, Dawson M, Mallin M. Ultrasoundguided, Bougie-assisted cricothyroidotomy: A description of a novel technique in cadaveric models. Acad Emerg Med 2012; 19:876-9. doi: 10.1111/j.1553-2712.2012.01391.x.

18. McGill J, Clinton JE, Ruiz E. Cricothyrotomy in the emergency department. Ann Emerg Med 1982; 11:361-4. doi: 10.1016/ S0196-0644(82)80362-4. 